\title{
Response of Dionaea muscipula J. Ellis to light stress in in vitro: physiological study
}

\author{
Krzysztof Tokarz $^{1}$ (D) Wojciech Makowski ${ }^{1} \cdot$ Rafal Banasiuk $^{2} \cdot$ Aleksandra Krolicka $^{2} \cdot$ Barbara Piwowarczyk $^{1}$
}

Received: 9 August 2017 / Accepted: 23 February 2018 / Published online: 28 February 2018

(c) The Author(s) 2018. This article is an open access publication

\begin{abstract}
Stress response of Dionaea muscipula J. Ellis to various light quality and quantity regimes, in the context of secondary metabolites production was determined. Venus Flytrap plants were cultivated in vitro in four different light regimes: fluorescence (50 $\mu \mathrm{mol} \times \mathrm{m}^{-2} \times \mathrm{s}^{-1}$ PPFD—control), fluorescence $\left(120 \mu \mathrm{mol} \times \mathrm{m}^{-2} \times \mathrm{s}^{-1}\right.$ PPFD) and white LED $\left(120 \mu \mathrm{mol} \times \mathrm{m}^{-2} \times \mathrm{s}^{-1}\right.$ PPFD) and in the darkness. Higher light intensity caused significant increase of membrane lipid peroxidation during the first 4 weeks of experiment. Whereas, light spectrum caused activation of defensive mechanisms. In the case of white LED, this mechanism was associated with the increased catalase activity and elevated synthesis of cinnamic acid derivatives, total phenols and plumbagin. While, in higher light intensity of fluorescence lamp, a reduction of chlorophyll content, and an increase amount of phenylopropanoids and plumbagin was observed. In turn, Venus Flytrap plants showed the highest activity of antioxidant enzymes, especially peroxidase, in the darkness. Higher concentration of plumbagin observed for the first time in response to different light quality and quantity, suggests that plumbagin is involved in photoprotection and/or in the antioxidant activity in Venus Flytrap tissue. Consequently, light might be used as an inorganic elicitator of 1,4-naphthoquinone derivatives and other phenolic compounds.
\end{abstract}

Keywords Abiotic stress $\cdot$ Droseraceae $\cdot$ Phenolic compounds $\cdot$ Plumbagin $\cdot$ Venus flytrap

$\begin{array}{ll}\text { Abbreviations } \\ \text { CAD } & \text { Cinnamic acid derivatives } \\ \text { Car } & \text { Carotenoids } \\ \text { CAT } & \text { Catalase } \\ \text { Chl } a & \text { Chlorophylls } a \\ \text { Chl } b & \text { Chlorophylls } b \\ \text { DW } & \text { Dry weight } \\ \text { FL } & \text { Fluorescence lamp } \\ \text { HPLC } & \text { High performance liquid chromatography } \\ \text { MDA } & \text { Malondialdehyde } \\ \text { OEC } & \text { Oxygen evolving center }\end{array}$

Communicated by Sergio J. Ochatt.

Krzysztof Tokarz

km.tokarz.ipbb@gmail.com

1 Unit of Botany and Plant Physiology, Faculty of Biotechnology and Horticulture, Institute of Plant Biology and Biotechnology, University of Agriculture in Krakow, al. 29 Listopada 54, 31-425 Kraków, Poland

2 Laboratory of Biologically Active Compounds, Department of Biotechnology, Intercollegiate Faculty of Biotechnology University of Gdansk and Medical University of Gdansk, University of Gdansk, Abrahama 58, 80-307 Gdańsk, Poland

$\begin{array}{ll}\text { POD } & \text { Peroxidase } \\ \text { PPFD } & \text { Photosynthetic photon flux density } \\ \text { PS II } & \text { Photosystem II } \\ \text { ROS } & \text { Reactive oxygen species } \\ \text { TBA } & \text { Thiobarbituric acid } \\ \text { TCA } & \text { Trichloroacetic acid } \\ \text { THF } & \text { Tetrahydrofuran } \\ \text { TPC } & \text { Total phenolic content } \\ \text { VAZ } & \text { Violaxanthin-antheraxanthin-zeaxanthin } \\ \text { WL } & \text { White LED light } \\ \text { Phy } & \text { Photoreceptors } \\ \text { LHCI } & \text { Light harvesting complex I } \\ \text { LHCII } & \text { Light harvesting complex II } \\ \text { Cry } & \text { Cryptohrome } \\ \text { Pho } & \text { Phototropin } \\ \text { Rib } & \text { Riboflavin } \\ \text { Phy } & \text { Phytohrome }\end{array}$




\section{Introduction}

Dionaea muscipula J. Ellis (Venus Flytrap) is a carnivorous plant from the Droseraceae family. This species is endemic plant from the North and South Carolina in United States (Hook 2001). According to Givnish's et al. (1984) cost-benefit model of carnivory, carnivorous plants are usually restricted to moistly, nutrient poor and sun exposed habitats, because only in such conditions carnivory is fully profitable. Modification of carnivorous plants leaves led to decrease photosynthesis efficiency and high breeding intensity due to energy demand in the process of attracting, capturing and digesting the prey (Pavlovic and Saganova 2015). In natural conditions carnivorous plants growing in open sun, can be exposed to various stress factors, in particular: light stress results from high light intensity, and changed light spectral composition (Tkalec et al. 2015). Light is a donor of the energy in the photosynthesis process and also mediates by photoreceptors in plant development affecting growth and metabolism regulation (Muller-Xing et al. 2014). Photophilous plants use for photosynthesis about $50 \%$ of incoming solar radiation. From 22 to $50 \%$ of energy is dissipated in the violaxanthin-antheraxanthin-zeaxanthin (VAZ) cycle. It is estimated that around 2-8\% of non-dissipated energy is a source of photooxidation (Szymanska et al. 2017). Therefore, high light intensity which, on the one hand, excesses photochemical efficiency of photosynthetic apparatus and on the other hand, is too high to be harmless dissipated by (VAZ) cycle leads to light stress (BarczakBrzyżek et al. 2017). In addition to the light intensity, its spectral composition is equally important. Changes in the light spectral composition affect the physiological processes and depending on the species, become a stimulator or stressor (Ouzounis et al. 2015b). The predominance of blue radiation, apart from anatomical changes, induces the chlorophyll formation and chloroplast development with a significant proportion of grana thylakoids, with high content of PS II and cytochrome $b_{6} f$ therein and high amount of Rubisco. Red light in contrast, leads to decrease of photosynthetic pigments content, formation of chloroplasts consisting mainly with stroma thylakoids with lesser PS II contribution but higher amount of PS I and cytochrome $b_{6} f$ (He et al. 2017). Thus changes in the structure of photosynthetic apparatus due to solar radiation composition may lead to light stress.

High light stress in plants, can cause oxidative damage (proteins, DNA and unsaturated fatty acids oxidation) and cells death. Most intensive production of reactive oxygen species (ROS), during excess light radiation, takes place on two-step photodamage reactions localized in oxygen evolving center (OEC) and PS II reaction centre in chloroplasts (Takahashi and Badger 2010; Zavafer et al. 2015). High light stress leads to perturbations in OEC, PSII reaction centres composition and efficiency, causing an excited molecules generation. Such molecules can interact with molecular oxygen leading to the formation of ROS e.g. superoxide and singlet-excited oxygen (Apel and Hirt 2004; Shumbe et al. 2016). The ROS reaction with lipids, particular with arachidonic acid which is peroxidized to finally form malondialdehyde (MDA), is generally known as "lipid peroxidation" and MDA content is widely accepted biomarker of oxidative stress (Tsikas 2017). In plant response to light stress, protection role against ROS on the one hand play antioxidant enzymes like: catalase (CAT), peroxidase (POD) and others and, on the other hand, secondary non enzymatic metabolites i.e. phenolic compounds and isoprenoids (Samuoliene et al. 2013). Antioxidant proteins' activity leads to scavenging ROS and allows plant to survive stress (Tattini et al. 2005). Moreover variation in spectral composition and intensity of light can modify concentration of biological active compounds in plants, like phenolics, flavonoids, anthocyanins, tannins and other plant secondary metabolites (Arena et al. 2016). That is why selected wavelengths are used in biotechnology and industry for biologically active compounds synthesis enhancement. For example, low and high intensity of UV-B radiation lead to increase production of glycyrrhizin in root tissue of Glycyrrhiza uralensis (Afreen et al. 2005) and under low light irradiance roots synthesized more glycyrrhizic acid, than control plants (Hou et al. 2010). Moreover, Kawka et al. (2017) showed that various light regimes caused differences in the quantity of phenolic compounds in shoot culture of Scutellaria lateriflora.

Plants from the Droseraceae family are sources of a few types of secondary metabolites: naphthoquinones, phenolic acids, flavonoid glucosides and flavonoids. On the one hand, phenolic compounds are the part of plant defence system during stress conditions. As a non-protein agent, they protect cells from oxidative-damages by scavenging ROS (quenching mechanism) and removing toxic substances from the cell environment (Shohael et al. 2006). Metabolites from phenols group are produced in cytoplasm and storage in vacuoles. During the presence of excess light or changed spectral composition these compounds can be accumulated in the epidermis cells, and act as a screening metabolites. Depending on the chemical structure of phenols, these compounds can have various absorption peak and may be protectants against various light wavelength (Takahashi and Badger 2010). Widhalm and Rhodes (2016), reported that 1,4-naphtoquinones can play important role in protection against photooxidation. In sexual fruiting bodies of filamentous fungi 1,4-naphtoquinones derivatives are accumulated as screening compounds. Phylloquinone (vitamin $\mathrm{K}_{1}$ ), which 
is 1,4-naphtoquinone, is one of the compounds involved in photosynthesis in plants and some microorganisms (Gross et al. 2006). Simultaneously, on the other hand, naphthoquinones as well as phenolic compounds have various medical properties. Therefore, genus: Dionaea and Drosera are medical plants used in folk medicine (Krolicka et al. 2008). Naphthoquinones are very diverse group of metabolites, synthesized by plants, microorganisms and some animals. In the plant kingdom these compounds, apart from Droseraceae family, are present in Nepenthaceae, Bignoniaceae, Plumbaginaceae, Boraginaceae, Juglandaceae, Dioncophyllaceae and Acanthaceae (Widhalm and Rhodes 2016). In carnivorous plants, plumbagin is produced in acetate-polymonate pathway, where precursors are acetyloCoA and malonyloCoA. Widhalm and Rhodes (2016) paid attention to several ecological properties of naphthoquinones. These redox active compounds are involved in allelopathy, plantmicrobial and plant-insect interactions. Derivates of the naphthoquinones play a protective role against predators (Tokunaga et al. 2004) and during digestion of prey in a leaf traps protect from putrefaction (Widhalm and Rhodes 2016).

Some scientists have characterized interactions of carnivorous plants with various environmental stress factors, like heavy metals (Babula et al. 2009), shade and nitrogen deficit (Thoren et al. 2003) in the context of carnivory syndrome or acclimation strategy. However, physiological response of carnivorous plants to light stress is still unknown. The aim of present study was to characterize $D$. muscipula response to various light quality and quantity regimes, in the context of secondary metabolites production-in particular phenolic compound. Present study is focused on biochemical mechanisms involved in light stress response and synthesis of biologically active compounds in D. muscipula plants. To our knowledge this is the first report on Venus Flytrap physiological and biochemical response to different light intensity and spectral composition.

\section{Materials and methods}

\section{Plant material}

Dionaea muscipula plantlets were obtained from the Botanical Garden of Wroclaw, Poland. The optimal medium for micropropagation of Venus flytrap consisted of $1 / 2 \mathrm{MS}$ medium (Murashige and Skoog 1962), 3\% sucrose, 0.8\% agar, $\mathrm{pH}$ 5.5. The plants used in experiment were grown in in vitro conditions in a growth chamber with $50 \mathrm{ml}$ of medium per flask. Tissue cultures were subcultured in 2 months intervals onto fresh medium. Plants were cultivated in temperature: $23 \pm 1{ }^{\circ} \mathrm{C}$, illumination: $50 \mu \mathrm{mol} \times \mathrm{m}^{-2} \times \mathrm{s}^{-1}$ photosynthetic photon flux density (PPFD) (Osram d.o.o., Zagreb), in $16 \mathrm{~h} / 8 \mathrm{~h}$ light/dark cycle.

\section{Experiment design and light treatments}

Shoots of established culture of D. muscipula were transferred onto fresh basal medium (the same as described in section above), ten plants per one flask. Culture vessels were closed with transparent PVC foil. Tissue cultured were placed in four various light regimes: fluorescence of $50 \mu \mathrm{mol} \times \mathrm{m}^{-2} \times \mathrm{s}^{-1}$ PPFD (control objects), darkness, fluorescence of $120 \mu \mathrm{mol} \times \mathrm{m}^{-2} \times \mathrm{s}^{-1}$ PPFD (fluorescence) and white LED light of $120 \mu \mathrm{mol} \times \mathrm{m}^{-2} \times \mathrm{s}^{-1}$ PPFD (white LED)
Fig. 1 Spectral characteristic of lights applied in experiment: white LED light (WL) and fluorescence lamp (FL)

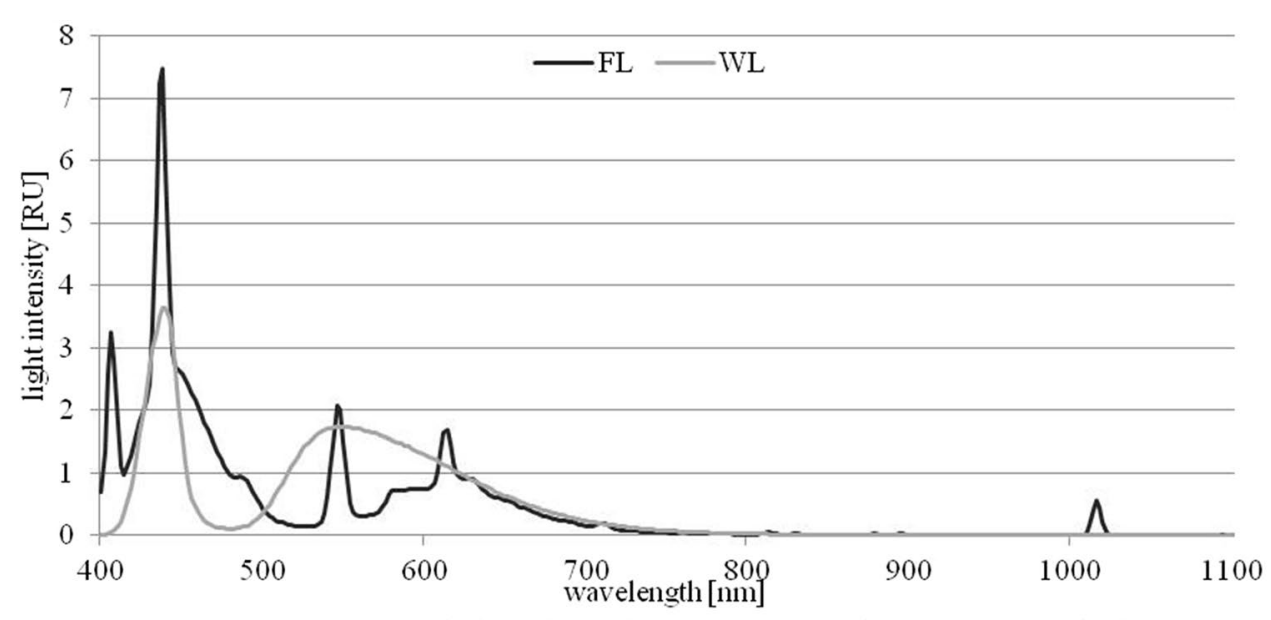

Percentage participation of selected wavelength ranges in whole used spectral radiation

\begin{tabular}{lccccccc}
\hline \multirow{2}{*}{ Light } & \multicolumn{7}{c}{ wavelength ranges (nm) } \\
\cline { 2 - 8 } WL & $\mathbf{4 0 0 - \mathbf { 4 5 0 }}$ & $\mathbf{4 5 2 - 5 0 0}$ & $\mathbf{5 0 2 - 5 5 0}$ & $\mathbf{5 5 2 - 6 0 0}$ & $\mathbf{6 0 2}-\mathbf{6 5 0}$ & $\mathbf{6 5 2 - 7 0 0}$ & $\mathbf{7 0 2 - 1 1 0 0}$ \\
FL & $42,7 \%$ & $19,4 \%$ & $20,0 \%$ & $24,3 \%$ & $14,8 \%$ & $6,3 \%$ & $3,4 \%$ \\
\hline
\end{tabular}


(Osram d.o.o., Zagreb). Spectral compositions of light radiation used in experiment and the percentage participation of selected wavelength ranges in whole used spectral radiation are presented in Fig. 1. On the basis of preliminary test results, $120 \mu \mathrm{mol} \times \mathrm{m}^{-2} \times \mathrm{s}^{-1}$ light intensity was selected as a stress factor. After 4 and 8 weeks of culture plant material were collected, subjected to growth analysis, frozen in liquid nitrogen, freeze-dried for $72 \mathrm{~h}$, homogenized and stored in $-20{ }^{\circ} \mathrm{C}$. Next various biochemical analysis were made on the plant material. Whole experiment was conducted in two independent repetitions.

\section{Growth assessment}

Growth index (GI) of fresh weight (FW) of plants were used to assess plant growth. GI was calculated based on the formula: $\mathrm{GI}=\left[\left(\mathrm{FW}_{\mathrm{b}}-\mathrm{FW}_{\mathrm{a}}\right) / \mathrm{FW}_{\mathrm{b}}\right] \times 100$, where $\mathrm{FW}_{\mathrm{a}}$ is the fresh weight of plant material at the beginning of the experiment, and $\mathrm{FW}_{\mathrm{b}}$ is fresh weight at the end of experiment.

\section{Photosynthetic pigment estimation}

The content of chlorophylls $a(\mathrm{Chl} a)$ and $b(\mathrm{Chl} b)$ and carotenoids (Car) was measured by spectrophotometric method of Lichtenthaler (1987) with modifications. Plant tissue $(10 \mathrm{mg}$ dry weight (DW)) were homogenized in $1 \mathrm{~mL}$ of $80 \%$ acetone with addition of magnesium chloride $\left(\mathrm{MgCl}_{2}\right)$ in $4{ }^{\circ} \mathrm{C}$. Samples were centrifuged for $15 \mathrm{~min}$ at $25,155 \times g$, in $4{ }^{\circ} \mathrm{C}$. Supernatant were collected and pellet were extracted two more times with $1 \mathrm{~mL}$ of $80 \%$ acetone till discoloration of plant tissue. After dilution, the absorbance of extract was measured at $663 \mathrm{~nm}(\mathrm{Chl} a), 646 \mathrm{~nm}(\mathrm{Chl} b)$ and $470 \mathrm{~nm}$ (Car), using Double Beam spectrophotometer U-2900 (Hitachi High-Technologies Corporation). Content of pigments was calculated according to Wellburn (1994). Additionally, total chlorophyll ( $\mathrm{Chl} a+b)$ content, ratio of chlorophylls $a$ to chlorophyll $b(\mathrm{Chl} a / b)$ and ratio of carotenoids to total chlorophylls ( $\mathrm{Car} / \mathrm{Chl} a+b)$ were calculated.

\section{Malonylodialdehyde content estimation}

The content of malonylodialdehyde (MDA) was determined according to Dhindsa et al. (1981), with slight modifications. Samples (10 mg DW of tissue) were homogenized in $1 \mathrm{~mL}$ of $0.1 \%$ trichloroacetic acid (TCA) in $4{ }^{\circ} \mathrm{C}$ and centrifuged for $5 \mathrm{~min}$ at $25,155 \times \mathrm{g}$. Supernatant $(0.2 \mathrm{~mL})$ were mixed with $0.8 \mathrm{~mL}$ of $20 \%$ TCA containing $0.5 \%$ thiobarbituric acid (TBA). Reaction mixtures were incubated in $95{ }^{\circ} \mathrm{C}$ for $30 \mathrm{~min}$ and centrifuged for $10 \mathrm{~min}$ at $25,155 \times \mathrm{g}$. The absorbance of supernatants was measured at 532 and $600 \mathrm{~nm}$. The value at $532 \mathrm{~nm}$ were reduced by the value at $600 \mathrm{~nm}$ (the correction value). Content of MDA was calculated with absorbance coefficient for MDA $\left(\varepsilon=155 \mathrm{mM} \mathrm{cm}^{-1}\right)$.

\section{Assessment of antioxidant enzymes activity}

Antioxidant enzymes activity was analyzed using spectrophotometric methods. Activity of catalase (CAT) was determined according to Bartosz (2006) and peroxidase (POD) according to Lück (1962). Tissue (10 mg DW) were homogenized at $4{ }^{\circ} \mathrm{C}$, in $1 \mathrm{~mL}$ of phosphate buffers with $\mathrm{pH} 7.0$ and 6.2 for CAT and POD activity analysis, respectively. Samples were centrifuged for $15 \mathrm{~min}$ at $25,155 \times g$, in $4{ }^{\circ} \mathrm{C}$. To determine the activity of CAT, $0.2 \mathrm{~mL}$ of supernatant was mixed with $1.8 \mathrm{~mL}$ of phosphate buffer $(\mathrm{pH} 7.0)$ and $1 \mathrm{~mL}$ of $\mathrm{H}_{2} \mathrm{O}_{2}$ solution in phosphate buffer. Absorbance of $\mathrm{H}_{2} \mathrm{O}_{2}$ decomposed by CAT was measured using wavelength $240 \mathrm{~nm}$, during $4 \mathrm{~min}$, in $1 \mathrm{~min}$ intervals. The results were presented as the amount of enzyme that decomposed $1 \mu \mathrm{mol}$ of $\mathrm{H}_{2} \mathrm{O}_{2}$ in 1 min.

Activity of POD was determined in reaction of $p$-phenyldiamine oxidation to phenazine by tested enzyme. $1.5 \mathrm{~mL}$ of phosphate buffer (pH 6.2), $0.5 \mathrm{~mL}$ of supernatant, $0.1 \mathrm{~mL}$ of $1 \%$ solution of $p$-phenyldiamine was mixed with $0.1 \mathrm{~mL}$ of $0.1 \% \mathrm{H}_{2} \mathrm{O}_{2}$. Absorbance was measured at $485 \mathrm{~nm}(0.1$ rise of absorbance correspond to one unit of POD activity).

\section{Phenolic compounds estimation}

The amount of total phenolic content (TPC) were measure using photometric method with Folin's reagent (Swain and Hillis 1959) with modifications. Plant material (10 mg DW) were homogenized in $1 \mathrm{ml}$ of $80 \%$ methanol in $4{ }^{\circ} \mathrm{C}$. Samples were centrifuged for $15 \mathrm{~min}\left(25,155 \times g, 4{ }^{\circ} \mathrm{C}\right)$. Diluted extract was mixed with $0.2 \mathrm{~mL}$ of Folin's reagent (Sigma-Aldrich Chemie, GmBH, Steinheim, Germany) and $1.6 \mathrm{~mL}$ of $5 \% \mathrm{Na}_{2} \mathrm{CO}_{3}$. After $20 \mathrm{~min}$ incubation in $40{ }^{\circ} \mathrm{C}$, the absorbance of samples were measured at $740 \mathrm{~nm}$. Chlorogenic acid was used as a reference standard and the results were expressed as milligram chlorogenic acid equivalents per $1 \mathrm{~g}$ of plant DW tissue.

\section{Cinnamic acid derivatives, flavonols and anthocyanins estimation}

Content of cinnamic acid derivatives (CAD), flavonols, and anthocyanins was determined using the spectrophotometric method according to Fukumoto and Mazza (2000). Plant material (10 mg DW) were homogenized in $1 \mathrm{~mL}$ of $80 \%$ methanol in $4{ }^{\circ} \mathrm{C}$. Samples were centrifuged for $15 \mathrm{~min}$ $\left(25,155 \times g, 4{ }^{\circ} \mathrm{C}\right)$. Diluted supernatant was mixed with: $0.25 \mathrm{~mL} 0.1 \% \mathrm{HCl}$ in $96 \% \mathrm{EtOH}$ and $4.55 \mathrm{~mL} 2 \% \mathrm{HCl}$ in $\mathrm{H}_{2} \mathrm{O}$. After $15 \mathrm{~min}$, the absorbance was measured at wavelengths of 320,360 , and $520 \mathrm{~nm}$. Using calibration curves made for caffeic acid, quercetin, and cyanidin, the content 
of CAD, flavonols, and anthocyanins was calculated. Results were expressed as milligram of CAD, flavonols and anthocyanins per $1 \mathrm{~g}$ of plant DW tissue.

\section{Plumbagin content estimation}

Plant material (10 mg DW) were homogenized in $0.5 \mathrm{~mL}$ of redistilled $\mathrm{H}_{2} \mathrm{O}$ and $0.5 \mathrm{~mL}$ of tetrahydrofuran (THF). Samples were shaken $15 \mathrm{~min}$ and $200 \mathrm{mg}$ of $\mathrm{NaCl}$ were added. Samples were shaken to dissolve the salt and centrifuged for $15 \min (25,155 \times g)$. Supernatant was collected for chromatographic analysis (HPLC). The chromatographic separation was carried out using Beckmann Gold System equipped with a Thermo Separations Spectra 100 variable wavelength detector and a Rheodyne 6-way injection valve. For the stationary phase an Agilent XDB-C18 $(4.6 \times 50 \mathrm{~mm}$, $1.8 \mu \mathrm{m}$ ) was used. The flow rate used was $1 \mathrm{~mL} \mathrm{~min}^{-1}$. The sample injection volume was $10 \mu \mathrm{L}$. The mobile phase for the analysis consisted of methanol as eluent $A$ and water as eluent $\mathrm{B}$. The separation was performed in isocratic conditions $(60 \% \mathrm{~A})$. The length of the analysis was $5 \mathrm{~min}$. The retention time of plumbagin was $2.78 \mathrm{~min}$. The separation was carried at room temperature. For determining concentration of the compounds 4 point 3 level standard curve was used. Monitoring was performed at $254 \mathrm{~nm}$. All analyses were performed in triplicate.

\section{Statistical analyses}

All results were subjected to one-way analysis of variance (ANOVA). The significant differences between means were determined using Duncan test at $p<0.05$ level. STATISTICA 12.0 (StatSoft Inc., Tulsa, OK, USA) was used to carry out statistical analyses. All physiological determinations were made in five replications.

\section{Results}

\section{Plant growth index}

GI of D. muscipula plants did not change significantly regardless high light intensity or changed spectral composition (Table 1). Only GI of plants cultivated 8 weeks in darkness decreased significantly in comparison to control conditions. Representative plants grown under the applied light conditions are shown on Fig. 2.

\section{Accumulation of photosynthetic pigments}

Different spectral composition and high light intensity had significant influence on photosynthetic pigment accumulation in Venus Flytrap. Total chlorophylls content $(\mathrm{Chl} a+b)$
Table 1 Effect of different light conditions and darkness on growth index in tissue culture of D. muscipula, after 4 and 8 weeks of culture

\begin{tabular}{lll}
\hline Light conditions & $\begin{array}{l}\text { Growth index }[\mathrm{RU} \pm \mathrm{SD}]( \pm \text { percentage of } \\
\text { control })\end{array}$ \\
\cline { 2 - 3 } 4 weeks & 8 weeks \\
\hline Control & $0.72^{\mathrm{a}} \pm 0.13$ & $2.19^{\mathrm{a}} \pm 0.18$ \\
Darkness & $0.89^{\mathrm{a}} \pm 0.05(+23.6)$ & $1.17^{\mathrm{b}} \pm 0.05(-46.6)$ \\
Fluorescence & $0.82^{\mathrm{a}} \pm 0.24(+13.9)$ & $2.14^{\mathrm{a}} \pm 0.21(-2.3)$ \\
White LED & $0.56^{\mathrm{a}} \pm 0.09(-22.2)$ & $2.35^{\mathrm{a}} \pm 0.70(+7.3)$ \\
\hline
\end{tabular}

Different letters significant difference at $p<0.05$ in each period; $R U$ rela units, $S D$ standard deviation

decreased in plants after 4 and 8 weeks of darkness. In high light intensity chlorophylls content decreased in plants from white LED after 4 weeks and from fluorescence after 8 weeks (Fig. 3). Similar changes were observed in $\mathrm{Chl} a / b$ ratio (Table 2). Car/Chl $a+b$ ratio increased after 4 weeks in cultures from each tested conditions. After 8 weeks this effect was observed only in darkness (Table 2).

Total carotenoids (Car) content decreased significantly in shoots after 4 and 8 weeks in darkness. There was no significant differences in carotenoids content between control culture and high lights intensity conditions cultures, either after 4 and 8 weeks (Fig. 3).

\section{MDA content}

After 4 weeks, MDA content increased significantly by $\sim 15$ and $40 \%$, respectively in plants from white LED and fluorescence, in comparison to control plants. In turn, D. muscipula plants from darkness accumulated significantly less MDA (Fig. 4). After 8 weeks of culture, decrease of MDA content was also observed in plants from darkness. No significant changes were noted in plants from the other light conditions (Fig. 4).

\section{Activity of antioxidant enzymes}

Depending on light conditions, various activity of POD and CAT was observed. After 4 weeks of D. muscipula culture, CAT activity was significantly higher in the darkness and fluorescence, compared to control plants. After 8 weeks of culture, significantly increase of CAT activity was observed in plants from white LED (Fig. 5). Darkness had a strong influence on POD activity in tested plants. In compared to control culture, either after 4 and 8 weeks, significantly enzyme activity was observed. In contrast, there was no significant differences in POD activity in white LED as well as fluorescence conditions (Fig. 5). 


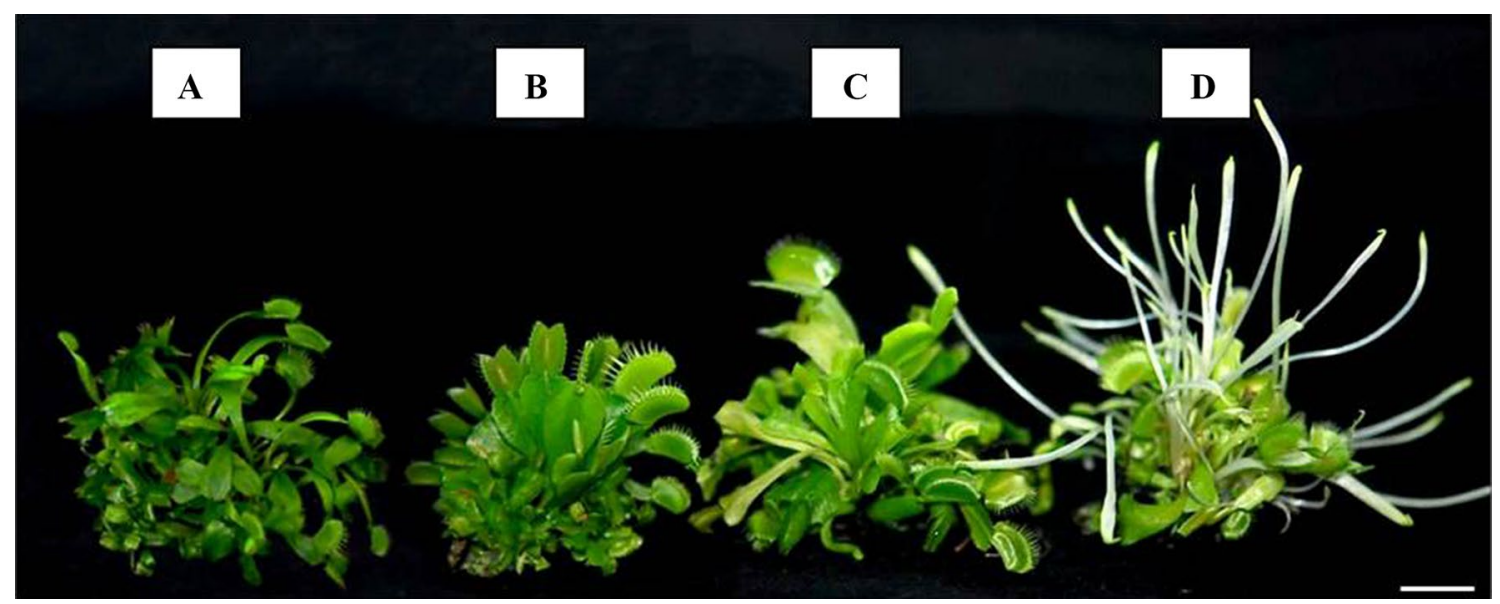

Fig. 2 Morphology of Dionaea muscipula plants growing on different light conditions after 8 weeks: a control, b fluorescence lamp, c white LED and d darkness

Fig. 3 Effect of different light conditions and darkness on chlorophyll $a(\mathrm{Chl} a)$, chlorophyll $b(\mathrm{Chl} b)$, chlorophyll $a+b(\mathrm{Chl} a+b)$ and carotenoids (Car) accumulation in tissue culture of D. muscipula, after 4 and 8 weeks. Different letters significant difference at $p<0.05$ in each parameter and period

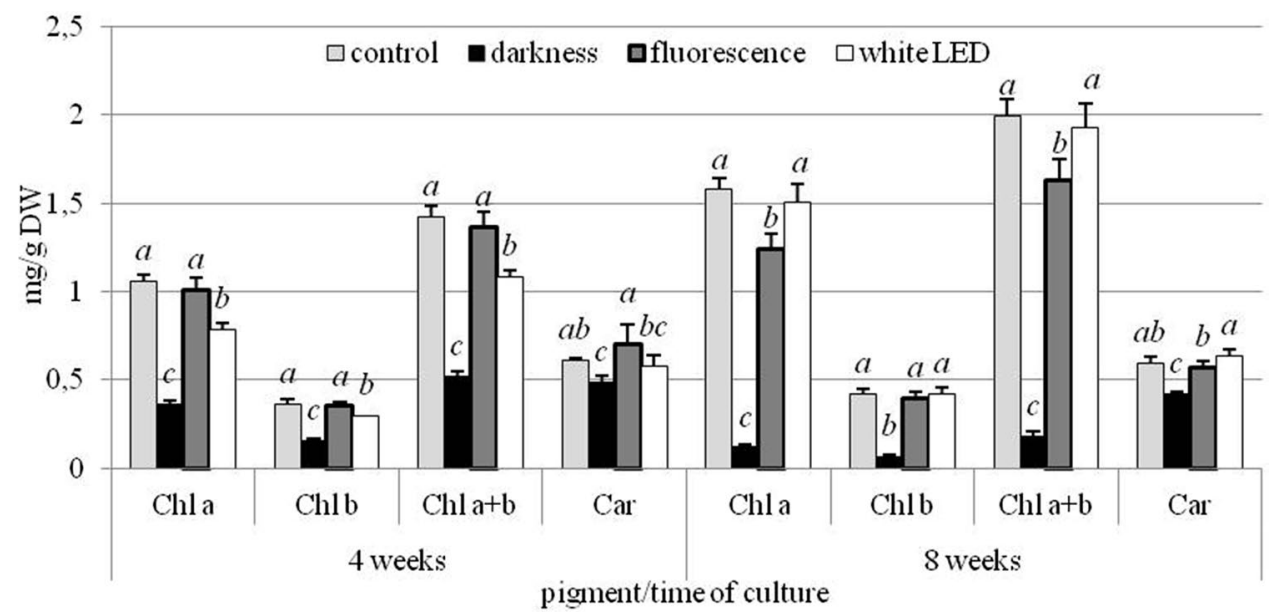

pigment/time of culture
Table 2 Effect of different light conditions and darkness on chlorophyll $a / b$ ratio $(\mathrm{Chl} a / b)$ and carotenoids/chlorophyll $a+b$ ratio (Car/ Chl $a+b$ ) in tissue culture of D. muscipula, after 4 and 8 weeks of culture

\begin{tabular}{|c|c|c|c|c|}
\hline \multirow{3}{*}{$\begin{array}{l}\text { Light condi- } \\
\text { tions }\end{array}$} & \multicolumn{4}{|c|}{ Pigment ratio $( \pm \mathrm{SD})$} \\
\hline & \multicolumn{2}{|l|}{ Chl $a / b$} & \multicolumn{2}{|l|}{ Car/Chl $a+b$} \\
\hline & 4 weeks & 8 weeks & 4 weeks & 8 weeks \\
\hline Control & $2.92^{\mathrm{a}} \pm 0.12$ & $3.76^{\mathrm{a}} \pm 0.11$ & $0.43^{c} \pm 0.02$ & $0.30^{\mathrm{b}} \pm 0.01$ \\
\hline Darkness & $2.33^{\mathrm{c}} \pm 0.10$ & $1.97^{\mathrm{c}} \pm 0.29$ & $0.94^{\mathrm{a}} \pm 0.05$ & $2.34^{\mathrm{a}} \pm 0.27$ \\
\hline Fluorescence & $2.88^{\mathrm{a}} \pm 0.11$ & $3.15^{\mathrm{b}} \pm 0.07$ & $0.51^{\mathrm{b}} \pm 0.06$ & $0.35^{\mathrm{b}} \pm 0.01$ \\
\hline White LED & $2.63^{\mathrm{b}} \pm 0.10$ & $3.55^{\mathrm{a}} \pm 0.11$ & $0.53^{\mathrm{b}} \pm 0.07$ & $0.33^{\mathrm{b}} \pm 0.01$ \\
\hline
\end{tabular}

Different letters significant difference at $p<0.05$ in each parameter and period; $S D$ standard deviation

\section{Accumulation of cinnamic acid derivatives, flavonols and anthocyanins}

Content of CAD significantly decreased after 4 and 8 weeks in the darkness and significantly increased in plants after 8 weeks in white LED and fluorescence. Concentration of flavonols as well as anthocyanins significantly decreased after 8 weeks in darkness (Table 3 ).

\section{Accumulation of phenolic compounds and plumbagin in various light conditions}

Results concerning accumulation of phenolic compounds and naphtoquinone-plumbagin showed that various light conditions used in experiment had significantly effect on secondary metabolism of $D$. muscipula plants. Plumbagin and total phenolic contents (TPC) in darkness significantly decreased both after 4 and 8 weeks of culture. Contrary to darkness, TPC increased significantly after 4 as well as 
Fig. 4 Effect of different light conditions and darkness on malondialdehyde (MDA) concentration in tissue culture of $D$. muscipula, after 4 and 8 weeks. Different letters significant difference at $p<0.05$ in each period

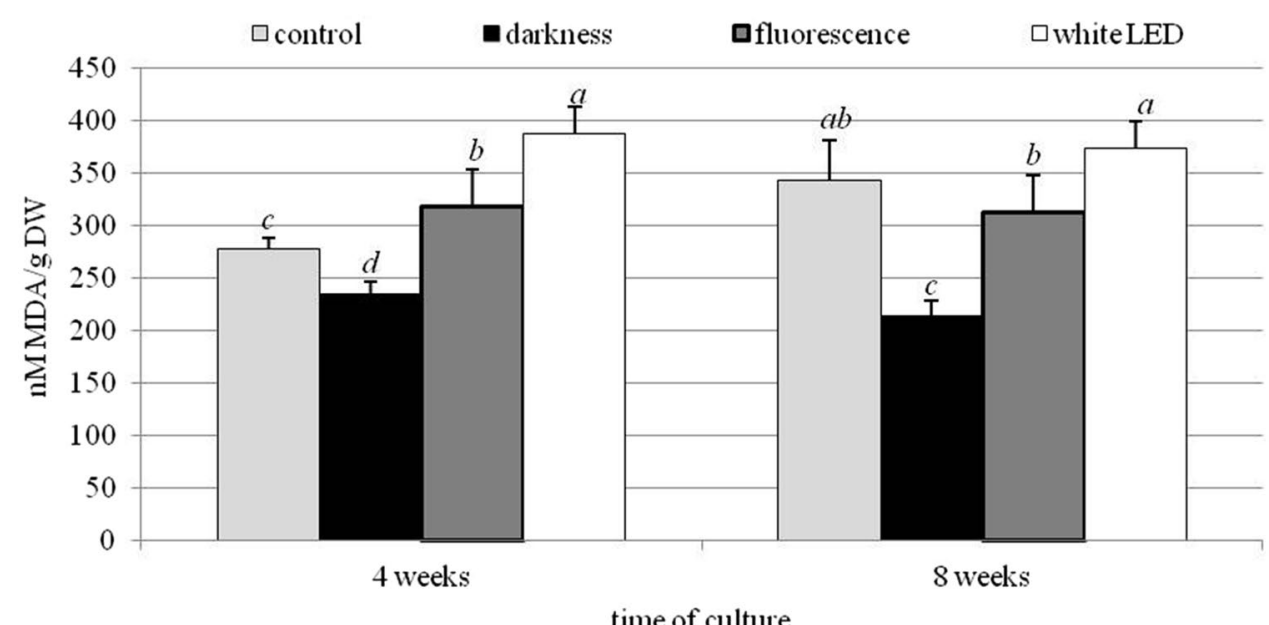

time of culture
Fig. 5 Effect of different light conditions and darkness on peroxidase (POD) and catalase (CAT) activity in tissue culture of D. muscipula, after 4 and 8 weeks. Different letters significant difference at $p<0.05$
Table 3 Effect of different light conditions and darkness on cinnamic acid derivatives (CAD), flavonols (F) and anthocyanins (A) content in shoots of D. muscipula, after 4 and 8 weeks of culture

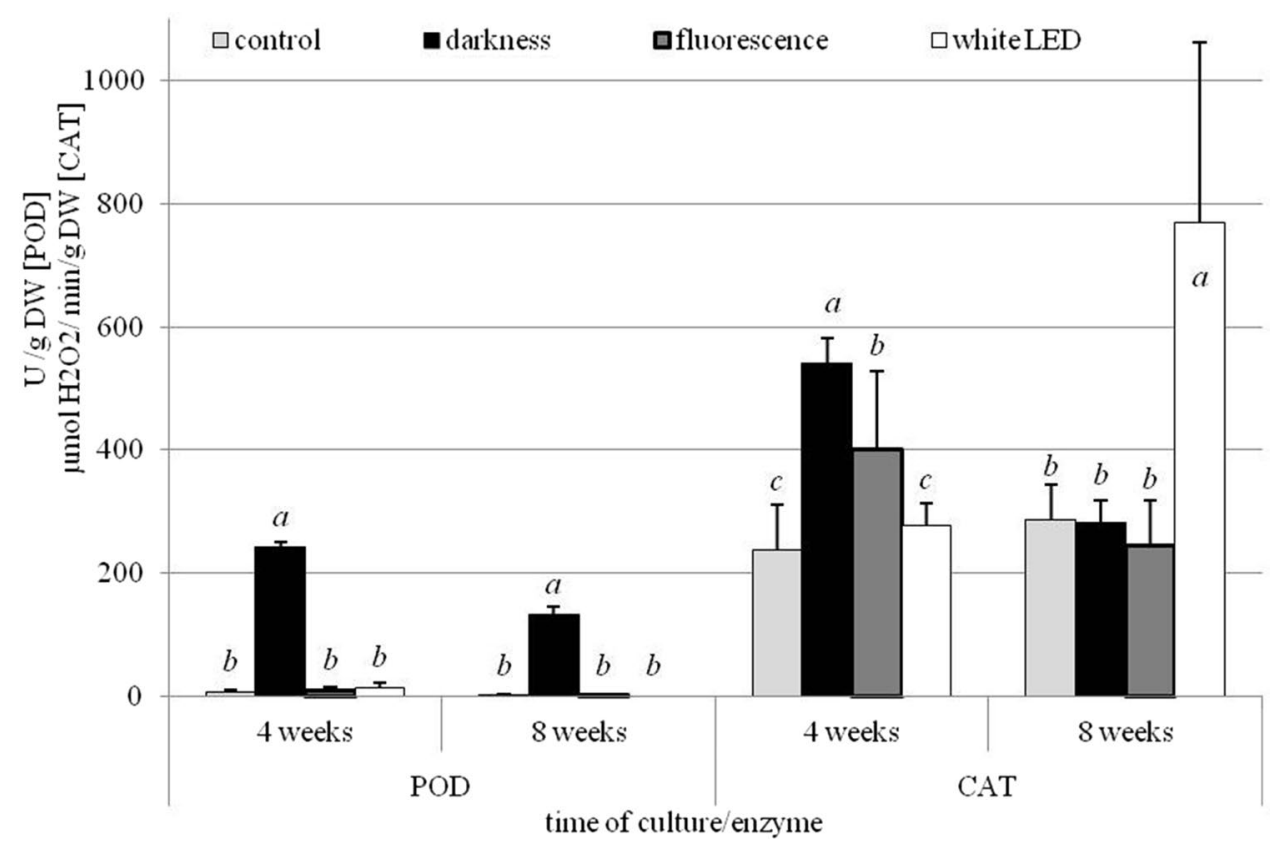

\begin{tabular}{|c|c|c|c|c|c|c|}
\hline \multirow[t]{2}{*}{ Light conditions } & \multicolumn{2}{|c|}{$\begin{array}{l}\text { Cinnamic acid derivatives } \\
\left(\mathrm{mg} \mathrm{g}^{-1} \mathrm{DW} \pm \mathrm{SD}\right)\end{array}$} & \multicolumn{2}{|c|}{$\begin{array}{l}\text { Flavonols }\left(\mathrm{mg} \mathrm{g}^{-1}\right. \\
\mathrm{DW} \pm \mathrm{SD})\end{array}$} & \multicolumn{2}{|c|}{$\begin{array}{l}\text { Anthocyanins }\left(\mathrm{mg} \mathrm{g}^{-1}\right. \\
\mathrm{DW} \pm \mathrm{SD})\end{array}$} \\
\hline & 4 weeks & 8 weeks & 4 weeks & 8 weeks & 4 weeks & 8 weeks \\
\hline Control & $3.38^{\mathrm{a}} \pm 0.14$ & $4.04^{c} \pm 0.10$ & $3.31^{\mathrm{a}} \pm 0.13$ & $3.14^{\mathrm{a}} \pm 0.15$ & $0.14^{\mathrm{a}} \pm 0.06$ & $0.16^{\mathrm{a}} \pm 0.02$ \\
\hline Darkness & $2.74^{b} \pm 0.64$ & $2.31^{\mathrm{d}} \pm 0.05$ & $3.22^{\mathrm{a}} \pm 0.98$ & $2.51^{\mathrm{b}} \pm 0.17$ & $0.17^{\mathrm{a}} \pm 0.23$ & $0.07^{b} \pm 0.02$ \\
\hline Fluorescence & $3.61^{\mathrm{a}} \pm 0.20$ & $4.33^{b} \pm 0.14$ & $3.32^{\mathrm{a}} \pm 0.24$ & $3.42^{\mathrm{a}} \pm 0.32$ & $0.18^{\mathrm{a}} \pm 0.03$ & $0.18^{\mathrm{a}} \pm 0.02$ \\
\hline White LED & $3.64^{\mathrm{a}} \pm 0.19$ & $4.85^{\mathrm{a}} \pm 0.28$ & $3.25^{\mathrm{a}} \pm 0.24$ & $3.22^{\mathrm{a}} \pm 0.26$ & $0.19^{\mathrm{a}} \pm 0.01$ & $0.17^{\mathrm{a}} \pm 0.02$ \\
\hline
\end{tabular}

Different letters significant difference at $p<0.05$ in each parameter and period; $S D$ standard deviation
8 weeks of culture in white LED and only after 4 weeks in fluorescence conditions (Fig. 6). Plumbagin content decreased significantly in darkness after 4 and 8 weeks. Nevertheless, significantly increase of plumbagin was observed in fluorescence after 4 weeks and in fluorescence and white LED after 8 weeks of culture (Fig. 7). 


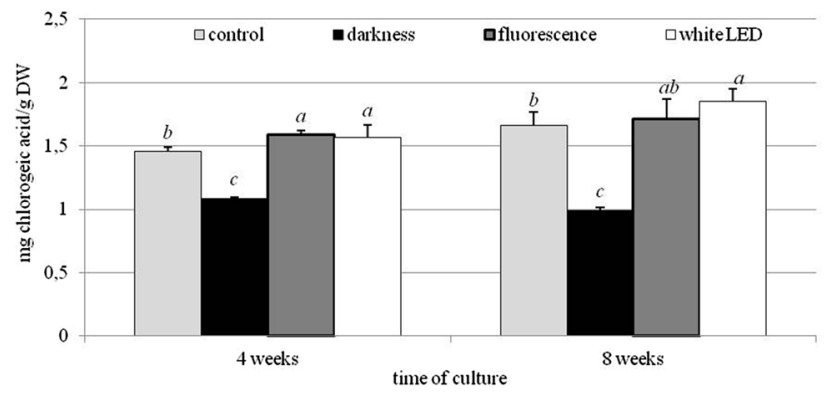

Fig. 6 Effect of different light conditions and darkness on total phenolic content (TPC) in tissue culture of D. muscipula, after 4 and 8 weeks. Chlorogenic acid was used as a reference standard and the results were expressed as $\mathrm{mg}$ chlorogenic acid equivalents per $1 \mathrm{~g}$ of plant DW tissue. Different letters significant difference at $p<0.05$ in each period

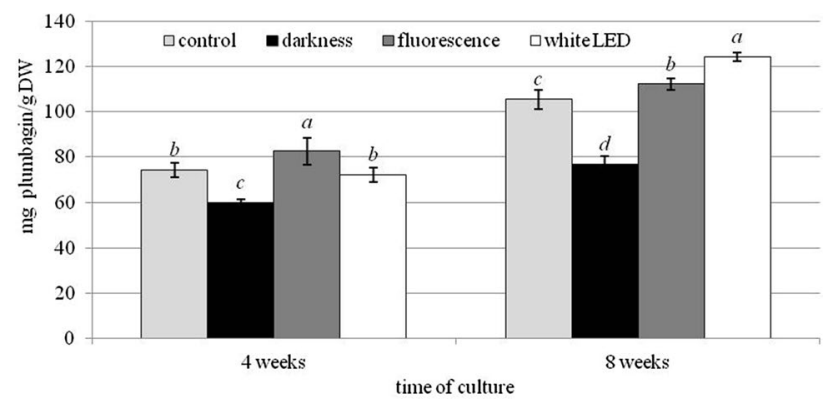

Fig. 7 Effect of different light conditions and darkness on plumbagin (P) production in tissue culture of D. muscipula, after 4 and 8 weeks. Different letters significant difference at $p<0.05$ in each period

\section{Discussion}

The quality and quantity of solar radiation affect plant growth and development via photosynthesis as well as, being a key factor sensed by photoreceptors, induce gene expression and cell components biosynthesis in morphogenesis process (Arena et al. 2016). Short wavelengths (between 380 and $450 \mathrm{~nm}$ ) activate the cryptochrome (Cry), phototropin (Pho) and riboflavin (Rib) receptors, while phytochrome (Phy) perceives red/far-red radiation (Yang et al. 2017). Since stress is defined as any changes of environmental factors leading to disorders in efficiency of metabolic processes, in case of photoautotrophic organism, both an excess of light, as well as its lack and rapid changes in its composition are elements of the broader concept cold as a light stress (Kruger et al. 1997). In presented experiments $D$. muscipula plants grew both under darkness as well as light conditions differing in intensity and spectral composition, but nevertheless, rich in the blue light and with small amount of red light. The monochromatic lights, or the prevalence of short-wave radiation leads to disturbances in the plant growth rate and biomass production, while a white light induces intensive plant growth and leaf biomass synthesis (Liu et al. 2018). A high proportion of blue light affects plant growth and development. Yang et al. (2017) reported that leaves' area and growth rate decreased in tobacco plants grown in blue light conditions. Similar effects were observed in lettuce, wheat and Doritaenopsis (Shin et al. 2008; Li and Kubota 2009). Moreover blue light reduced growth rate of tobacco, radish, pea and wheat (Cope and Bugbee 2013; Yang et al. 2017). Contrary, higher participation of blue light in the light spectrum led to the plants' dry mass increase, with no significant effect on growth rate of different plant species (Ouzounis et al. 2014, 2015a; Szopa and Ekiert 2016). In our experiments there were no changes in the growth rate both after 4 and 8 weeks of culture regardless of the light sources, but light quality and quantity affected plant development - plants from white LED became more compact. No change in the growth rate of Venus Flytrap plants might be due to the adaptation of this species to high blue light contribution in light spectrum what was observed by other authors in lettuce plant ( $L a c$ tuca sativa) (Ouzounis et al. 2014, 2015a). In the darkness the red/far-red ration is very low leading to inhibition of multitude processes regulated by Phy photoreceptor family, in particular growth and development (Krahmer et al. 2018; Song and Li 2018). On the one hand, the level of soluble sugars, amino acids and a few groups of secondary metabolisms increase, on the other, accumulation of the starch, proteins, chlorophyll and carotenoids decrease causing decrease rate of plant growth and development (Han et al. 2017; Krahmer et al. 2018). In our experiments in the darkness, a statistically significant decrease in the plant growth rate after 8 weeks of culture was observed what was related to the inconsiderable etiolated shoots extension in relation to the whole plant biomass.

Despite its key functions in photosynthesis and morphogenetic regulation of the plant growth rate and development, light due to its frequent and rapid changes in intensity and spectral composition is the most common stress factor for the plant (Taiz et al. 2015). Changes in the quality and quantity of radiation affect the structure, composition and functionality of photosynthetic apparatus modifying the chloroplasts, chlorophyll and carotenoids quantity and their mutual relationship (Anderson et al. 2008; Ballottari et al. 2007; Esteban et al. 2015). During exposition to excess light, chloroplasts can change positions in cells compartments to avoid overabundance of energy. Moreover, in the chloroplasts may occur rearrangement of existing structures and in longer period selective synthesis and chloroplast components degradation can be observed (Bailey et al. 2001). Absorption of excess energy can lead to photoinhibition and 
reduce the photosynthetic efficiency of PSII (Tkalec et al. 2015). Moreover, light stress might lead to disorders in photosynthetic pigments quality and quantity. Changes in the $\mathrm{Chl} a$ and $\mathrm{Chl} b$ content are associated with the process of acclimation to the changing light conditions. Chl $a$ is an immanent both in the Light Harvesting Complexes (LHCI and LHCII) as well in the reaction centers of the photosystems (PSI and PSII) whereas Chl $b$ is a part only in the LHCs. Decrease in the Chl $a+b$ content and/or low value of $\mathrm{Chl} a / b$ ratio indicate a reduction in the LHCII antennas size what is a paramount indicator of photosynthetic apparatus acclimation to light stress (Esteban et al. 2015; Morosinotto and Bassi 2012). In addition $\mathrm{Chl} b$ decrease in plants expose to high light intensity indicates chlorophyll destruction (Tkalec et al. 2015). Also spectral composition affects the content of photosynthetic pigments and their mutual relations. Yang et al. (2017) reported that tobacco plants grown under blue light had a significantly lower chlorophyll and carotenoids content compared to control. At the same time, the $\mathrm{Chl} a / b$ ratio in these plants was higher than that under white light ones, showing that the acclimatization strategy of tobacco to high-energy blue light is related to the effective reduction of the photosynthetic antennas size of as well as the number of active reaction centres. In contrary, Ouzounis et al. (2015a) in lettuce plants cultivated under sunlight supplemented with blue radiation observed significant increase of photosynthetic pigments compare to control, indicating that plant acclimation to high-energy radiation is a complex process, requiring contribution of wider spectrum radiation. In our experiment, light conditions led to lower chlorophyll concentration in D. muscipula plants but these changes dependent on light spectral composition. After 4 weeks the reduction in total chlorophyll content as well as in Chl $a / b$ ratio was caused by white LED, whereas after 8 weeks similar changes were observed in fluorescence light condition. The decrease in chlorophyll content combined with a lower Chl $a / b$ ratio indicates a change of antennas size, as well as the reconstruction of photosystem reaction centers (Esteban et al. 2015). The changes under white LED observed after 4 weeks of culture resulted from the smaller blue light and the greater green light participation in its spectrum (see Fig. 1). Blue radiation using Cry and Pho induces chlorophyll synthesis and supports the acclimation of the photosynthetic apparatus for light stress, while green radiation, which is also sensed by Cry reserves blue light-induced responses (Ouzounis et al. 2015a). As a consequence after 4 weeks of high light treatment $D$. muscipula grown under white LED had the lowest chlorophyll content due to both lower synthesis rate as well as photooxidation process. In contrary, 8 weeks high light treatment under fluorescence abundants in blue light caused chlorophyll content decreased due to photosynthetic apparatus reorganization. In this context very meaning is Chl $a$ and $\mathrm{Chl} a / b$ ratio decrease without
Chl $b$ changes, what can suggest the reduction of antennas and the reconstruction of photosystems (Dai et al. 2009). Changes in photosystems compositions are one of the possible way to acclimation in excess light conditions (Walters 2005). Tkalec et al. (2015) showed that outdoor growing plants of Drosera rotundifolia accumulated less $\mathrm{Chl} a$, than indoor growing ones, due to on the one hand small amount energy available in growing chambers and, on the other hand to avoid the possible negative effect of excess energy. Total content of Chl $a$ and $\mathrm{Chl} b$ significantly decreased in plants of Ligustrum vulgare and Phillyrea latifolia exposed to excess light (Tattini et al. 2005). In the same study Car/ Chl $a+b$ ratio significantly increased in both examined species. This parameter increased also in D. rotundifolia plants from outdoor conditions, comparing to indoor (Tkalec et al. 2015). Similarly, our experiment also showed the significant increase of $\mathrm{Car} / \mathrm{Chl} a+b$ ratio in high light intensity after 4 weeks. Car/Chl $a+b$ ratio was proposed as an indicator of VAZ cycle activity. VAZ process is based on transformation of violaxanthin to zeaxanthin, which have the ability to conversion of excess energy to heat (Szymanska et al. 2017). Our study showed, that after 4 weeks of Venus Flytrap culture, exposition to high light conducted to activation of VAZ cycle, degradation of chlorophyll and the reconstruction of photosystems. Such reaction to light stress probably led to new way of dealing with presence of high light energy. Smaller photosystemes antennas and lover concentration of Chl $a$ allow to acclimation of D. muscipula photosystems to presence of light stress.

In mature plants, in the darkness after the initial shortterm growth rate increase, the senescence photosynthetic apparatus degradation as well as a growth rate reduction follow (Krahmer et al. 2018; Krupinska et al. 2012). It leads to an dramatic drop in the chlorophyll content due to chloroplast degradation (Krupinska et al. 2012). Also in our experiment photosynthetic pigments content in D. muscipula cultivated in the darkness decreased. Light stress caused by both darkness as well as high light intensity and variation in its spectral composition may lead to increased ROS production and oxidative stress. A useful biomarker for estimating the level of oxidative stress is the MDA content, which is the product of the lipid peroxidation (Shohael et al. 2006). Tattini et al. (2005) showed that $L$. vulgare and P. latifolia plants under high solar radiation accumulated more MDA in comparison to the plants which grew in shadow. Moreover, also light quality may cause oxidative stress. Yu et al. (2017) reported significant increase of lipid peroxidation in Camptotheca acuminata seedlings grown under blue light. Both applied light conditions (white LED and fluorescence) after 4 weeks of our experiment, caused increased MDA concentration in Venus Flytrap tissue. Reduced chlorophyll content in D. muscipula tissue under white LED and fluorescence may result from disintegration of chloroplasts membranes 
caused by unsaturated fatty acids oxidation (Takahashi and Badger 2010). However, not only quantity of delivered light energy can modify MDA content in plant tissue. Shohael et al. (2006) shown that the highest MDA content have been observed in embryos of Eleutherococcus senticosus cultivated under red LED light compared to fluorescent light or darkness. Tissue culture of D. muscipula had the highest level of MDA in white LED, what can evidence the highest level of ROS production in this conditions. ROS, formed under light stress induce activity of plant antioxidant system i.e.: by phenols accumulation and enzymes' activity increase (Torres-Franklin et al. 2008). Ibrahim et al. (2014), in Labisia pumila Benth plants exposed to irradiance and $\mathrm{CO}_{2}$ concentration gradient, demonstrated significantly negative correlation of MDA level with TPC and flavonols accumulation. They reported the highest MDA level in plants under low radiation and high $\mathrm{CO}_{2}$ concentration. While under high radiation and the same $\mathrm{CO}_{2}$ concentration, they observed decrease of MDA but significant increase of phenolic compounds accumulation. Increased level of $\mathrm{CO}_{2}$ during exposition to high light intensity can cause probably reduction of photorespiration and ROS production. In contrast, our results showed increased MDA level leading to the TPC increased in D. muscipula in response to high light intensity. Increased ROS and MDA level could be an indispensable factor for some secondary metabolites production, as postulated by Ibrahim and Jaafar (2012). Nonetheless, different acclimation strategies to changed light conditions in D. muscipula and $L$. pumila results probably from their natural origin $-L$. pumila occurs in tropical forests of Malaysia.

Examined light conditions did not affected POD activity, while CAT activity increased in fluorescence (after 4 weeks) and white LED (after 8 weeks). Golemiec et al. (2014) reported significant increase in Catl and Cat3 genes expression as well as higher catalase and peroxidase activity in tobacco plants in response to high light and high light + hydrogen peroxide treatments respectively. Wang et al. (2017) observed enhanced activity of antioxidant enzymes together with increased level of MDA and $\mathrm{H}_{2} \mathrm{O}_{2}$ in Changium smyrnioides plants under full sunlight. In presented experiments, the highest activity of POD (in both periods) and CAT (after 4 weeks) was noted in plants cultivated in darkness, in which level of MDA decreased significantly. This may prove, on the one hand, the highest amount of ROS production in the darkness, caused by both increased dark respiration intensity as well as progressive photosynthetic apparatus degradation due to senescence, as reported Krupinska et al. (2012), but on the other, the most effective action of antioxidant enzymes in etiolated plants of D. muscipula. In turn, POD is involved in synthesis of substances building the cell wall (Lin and Kao 2001). Elongation growth of cells in the darkness, and development of cell wall structure may influence the high POD activity in
Venus Flytrap. Furthermore, the lowest level of TPC, CAD, flavonols, anthocyanins and plumbagin accumulation in this carnivorous plant growing in the darkness suggests, that response to high level of ROS production in limited light conditions is based on antioxidant enzymes activity and synthesis of phenolic compounds is associated with light presence.

Dionaea muscipula is known as the plant reach in many derivatives of phenolic compounds: various phenolic acids, flavonoids and naphtoquinones (Gaascht et al. 2013). Until now, researchers focused mainly on $D$. muscipula medical properties, and importance of those compounds in response system to abiotic stress factors in this plant have not been clarified. In presented study we proved that concentration of various phenolic derivatives is connected with light conditions: increased TPC in fluorescence after 4 weeks and in white LED after 4 and 8 weeks of culture. After 8 weeks in white LED and fluorescence also CAD content (phenylopropanoides) have increased. Furthermore, study of Tkalec et al. (2015) showed that outdoor growing plants of D. rotundifolia accumulated more phenolic compounds, anthocyanins and flavonols than indoor growing plants. Anthocyanins and flavonols are known mostly as the protectants vs UV-A and UV-B radiation, which are the part of spectral composition of natural solar radiation (Agati and Tattini 2010). They are also known as strong antioxidant compounds, which have the ability to inhibit ROS generation and act as the antioxidant molecules (Agati et al. 2012). In Venus Flytrap we did not observed changes in anthocyanins and flavonols concentration in high light conditions, probably because of the different acclimation strategy of this plant to excess energy and various radiation composition.

Relations between antioxidant enzymes and phenolic compounds activity in the response to stress conditions in plants needs further research. Severe stress factor could decrease activity of antioxidant enzymes and contribute to elevated activity of phenolic compounds in response to oxidative damage (Agati et al. 2012; Mamedes-Rodrigues et al. 2017). Our results demonstrated, that increased unsaturated fatty acid oxidation (MDA) after 4 weeks of high light intensity was reduced after next 4 weeks of experiment. This can indicate the effective defense system in $D$. muscipula, despite that only CAT activity was affected by light conditions applied. Increased level of TPC, as well as CAD after 8 weeks of experiment showed participation of phenolic compounds derivatives in response of Venus Flytrap to changed light conditions. Saito and Mizukami (2002) reported that presence of light can decrease concentration of naphtoquinones in plant tissue culture. In contrary, Silja et al. (2014) reported increased content of plumbagin in response to biotic stressors. However, level of plumbagin in D. muscipula tissue culture increased in white LED and fluorescence after 8 weeks and decreased 
in darkness. Moreover, the highest concentration of plumbagin was obtained in plants grew 8 weeks under white LED, together with elevated TPC, CAD content and CAT activity. Widhalm and Rhodes (2016), reported various ecophysiological roles of 1,4-naphtoquinones derivatives, but their role in acclimation mechanisms to changed abiotic conditions is still unknown. Our research showed that production of plumbagin in D. muscipula in in vitro, as well as the other phenolic compounds, is affected by light quality and quantity. This suggests that 1,4-naphtoquinones are involved not only in allelopathy and biotic stress response, but also could play important role in photoprotection and/or in the antioxidant activity in Venus Flytrap tissue. Until now, photoprotection role of 1,4-naphtoquinones derivatives was postulated by Widhalm and Rhodes (2016), as the screening metabolites in filamentous fungi against shortwave radiation. Presented experiment showed, that plumbagin takes part in the response strategy of $D$. muscipula to different light conditions. On the other hand, to determine how plumbagin works in defence system of carnivorous plants under abiotic stress (as the antioxidant compound or/and screening metabolite) further studies are necessary. After all, changes observed in phenolic compounds concentration affected by different light quality and quantity provide the basis for the use of light as the elicitor of biologically active compounds in plants from Droseraceae family.

\section{Conclusion}

In the presented study the stress response strategy of Venus Flytrap in in vitro culture to various light spectra and intensities, in the context of phenolic compounds production-in particular plumbagin was examined. For the first time the significant increase of cinnamic acid derivatives and plumbagin synthesis in association with higher light intensity and spectral composition was observed. It might suggest that 1,4-naphtoquinones are involved in photoprotection and/or in the antioxidant activity in Venus Flytrap tissue. Moreover, it seems that appropriate light quality and quantity might be use as an inorganic elicitor for synthesis of 1,4-naphthoquinone derivatives.

Acknowledgements This research was financed by the Ministry of Science and Higher Education of the Republic of Poland (DS 3500 and DS 530-M035-D673-18).

Author Contributions KT conceived and designed the experiment. KT and WM contributed to data acquisition, interpreted and discussed the data and wrote the manuscript. BP contributed to data acquisition, performed statistical analyses of the data and prepared graphical part of the manuscript. RB developed the analytical method for determination of plumbagin and analyzed HPLC data. AK advised on experimental design, checked and corrected the manuscript. All authors proofread the manuscript, agreed on its contents and consented to submit it.

\section{Compliance with ethical standards}

Conflict of interest The authors declare that they have no conflict of interest.

Open Access This article is distributed under the terms of the Creative Commons Attribution 4.0 International License (http://creativeco mmons.org/licenses/by/4.0/), which permits unrestricted use, distribution, and reproduction in any medium, provided you give appropriate credit to the original author(s) and the source, provide a link to the Creative Commons license, and indicate if changes were made.

\section{References}

Afreen F, Zobayed SMA, Kozai T (2005) Spectral quality and UV-B stress stimulate glycyrrhizin concentration of Glycyrrhiza uralensis in hydroponic and pot system. Plant Physiol Biochem 43:1074-1081

Agati G, Tattini M (2010) Multiple functional roles of flavonoids in photoprotection. New Phytol 186:786-793

Agati G, Azzarello E, Pollastri S, Tattini M (2012) Flavonoids as antioxidants in plants: location and functional significance. Plant Sci 196:67-76

Anderson JM, Chow WS, De las Rivas J (2008) Dynamic flexibility in the structure and function of photosystem II in higher plant thylakoid membranes: the grana enigma. Photosynth Res 98:575-587

Apel K, Hirt H (2004) Reactive oxygen species: metabolism, oxidative stress, and signal transduction. Ann Rev Plant Biol 55:373-399

Arena C, Tsonev T, Doneva D et al (2016) The effect of light quality on growth, photosynthesis, leaf anatomy and volatile isoprenoids of a monoterpene-emmiting herbaceous species (Solanum lycopersicum L.) and an isoprene-emitting tree (Platanus orientalis L.). Environ Exp Bot 130:122-132

Babula P, Ryant P, Adam V, Zehnalek J, Havel L, Kizek R (2009) The role of sulphur in cadmium(II) ions detoxification demonstrated in in vitro model: Dionaea muscipula Ell. Environ Chem Lett 7:353-361

Bailey S, Walters RG, Jansson S, Horton P (2001) Acclimation of Arabidopsis thaliana to the light environment: the existence of separate low light and high light responses. Planta 213:794-801

Ballottari M, Dall'Osto L, Morosinoto T, Bassi R (2007) Contrasting behavior of higher plant photosystem I and II antenna systems during acclimation. J Biol Chem 282:8947-8958

Barczak-Brzyżek AK, Kiełkiewicz M, Gawroński P, Kot K, Filipecki M, Karpińska B et al (2017) Cross-talk between high light stress and plant defence to the two-spotted spider mite in Arabidopsis thaliana. Exp Appl Acarol 73:177

Bartosz G (2006) Another side of oxygen: free radicals in nature. Wydawnictwo Naukowe PWN, Warsaw (Polish)

Cope KR, Bugbee B (2013) Spectral effects of three types of white light-emitting diodes on plant growth and development: absolute versus relative amounts of blue light. HortScience 48:504-509

Dai Y, Shen Z, Liu Y, Hannaway D, Lu H (2009) Effects of shade treatments on the photosynthetic capacity, chlorophyll fluorescence, and chlorophyll content of Tetrastigma hemsleyanum Diels et Gilg. Environ Exp Bot 65:177-182

Dhindsa RH, Plumb-Dhindsa R, Thorpe TA (1981) Leaf senescence correlated with increased level of membrane permeability, lipid peroxidation and decreased level of SOD and CAT. J Exp Bot 32:93-101

Esteban R, Barrutia O, Artetxe U, Fernández-Marín B, Hernández A, García-Plazaola JI (2015) Internal and external factors affecting 
photosynthetic pigment composition in plants: a meta-analytical approach. New Phytol 206(1):268-280

Fukumoto LR, Mazza G (2000) Assessing antioxidant and prooxidant activities of phenolic compounds. J Agric Food Chem 48:3597-3604

Gaascht F, Dicato M, Diederich M (2013) Venus flytrap (Dionaea muscipula Solander ex Ellis) contains powerful compounds that prevent and cure cancer. Front Oncol 3:202

Givnish TJ, Burkhardt EL, Happel RE, Weintraub JD (1984) Carnivory in the bromeliad Brocchinia reducta, with a cost/benefit model for the general restriction of carnivorous plants to sunny, moist nutrient-poor habitats. Am Nat 124:479-497

Golemiec E, Tokarz K, Wielanek M, Niewiadomska E (2014) A dissection of the effects of ethylene, $\mathrm{H} 2 \mathrm{O} 2$ and high irradiance on antioxidants and several genes associated with stress and senescence in tobacco leaves. J Plant Physiol 171:269-275

Gross J, Cho WK, Lezhneva L et al (2006) A plant locus essential for phylloquinone (vitamin $\mathrm{K}_{1}$ ) biosynthesis originated from a fusion of four Eubacterial genes. J Biol Chem 281(25):17189-17196

Han X, Tohge T, Lalor P (2017) Phytochrome A and B regulate primary metabolism in Arabidopsis leaves in response to light. Front Plant Sci 8:1394

He J, Qin L, Chong ELC (2017) Plant growth and photosynthetic characteristics of Mesembryanthemum crystallinum grown aeroponically under different blue- and red-LEDs. Front Plant Sci 8:361

Hook ILI (2001) Naphthoquinone contents of in vitro cultured plants and cell suspensions of Dionaea muscipula and Drosera species. Plant Cell Tiss Organ Cult 67:281-285

Hou J, Li W, Zheng Q, Wang WQ, Xiao B, Xing D (2010) Effect of low light intensity on growth and accumulation of secondary metabolites in roots of Glycyrrhiza uralensis Fisch. Biochem Syst Ecol 38:160-168

Ibrahim MH, Jaafar HZE (2012) Primary, secondary metabolites, $\mathrm{H}_{2} \mathrm{O}_{2}$, malondialdehyde and photosynthetic responses of Orthosiphon stimaneus Benth. to different irradiance levels. Molecules 17:1159-1176

Ibrahim MH, Jaafar HZE, Karimi E, Ghasemzadeh A (2014) Allocation of secondary metabolites, photosynthetic capacity, and antioxidant activity of kacip fatimah (Labisia pumila Benth) in response to $\mathrm{CO}_{2}$ and light intensity. Sci World $\mathrm{J}$ 1:13

Kawka B, Kwiecien I, Ekiert H (2017) Influence of culture medium composition and light conditions on the accumulation of bioactive compounds in shoot cultures of Scutellaria lateriflora L. (American Skullcap) grown in vitro. Appl Biochem Biotechnol 183:1414-1425

Krahmer J, Ganpudi A, Abbas A, Romanowski A, Halliday KJ (2018) Phytochrome, carbon sensing, metabolism, and plant growth plasticity. Plant Physiol 176(2):1039-1048

Krolicka A, Szpitter A, Gilgenast E, Romanik G, Kaminski M, Lojkowska E (2008) Stimulation of antibacterial naphthoquinones and flavonoids accumulation in carnivorous plants grown in vitro by addition of elicitors. Enzyme Microbial Technol 42:216-221

Kruger GH, Tsimilli-Michael M, Strasser RJ (1997) Light stress provokes plastic and elastic modifications in structure and function of photosystem II in camellia leaves. Physiol Plant 101(2):265-277

Krupinska K, Mulisch M, Hollmann J (2012) An alternative strategy of dismantling of the chloroplasts during leaf senescence observed in a high-yield variety of barley. Physiol Plant 144(2):189-200

Li Q, Kubota Ch (2009) Effects of supplemental light quality on growth and phytochemicals of baby leaf lettuce. Env Exp Bot 67:59-64

Lichtenthaler HK (1987) Chlorophylls and carotenoids: pigments of photosynthetic biomembranes. Methods Enzymol 148:350-382

Lin CC, Kao CH (2001) Cell wall peroxidase activity, hydrogen peroxide level and $\mathrm{NaCl}$-inhibited root growth of rice seedling. Plant Soil 230:135-143
Liu Y, Fang S, Yang W, Shang X, Fu X (2018) Light quality affects flavonoid production and related gene expression in Cyclocarya paliurus. J Photochem Photobiol B 179:66-73

Lück H (1962) Methoden der enzymatischen analyse. Verlag Chemie $\mathrm{GmbH}$, Weinheim

Mamedes-Rodrigues TC, Batista DS, Napoleão TA et al (2017) Lignin and cellulose synthesis and antioxidative defense mechanisms are affected by light quality in Brachypodium distachyon. Plant Cell Tiss Organ Cult. https://doi.org/10.1007/s11240-017-1356-7

Morosinotto T, Bassi R (2012) Assembly of light harvesting pigmentprotein complexes in photosynthetic eukaryotes. In: Eaton-Rye JJ, Tripathy BC, Sharkey TD (eds) Photosynthesis: plastid biology, energy conversion and carbon assimilation, advances in photosynthesis and respiration. Dordrecht, Springer, pp 113-126

Muller-Xing R, Xing Q, Goodrich J (2014) Footprints of the sun: memory of UV and light stress in plants. Front Plant Sci 5:474

Murashige T, Skoog F (1962) A revised medium for rapid growth and bioassays with tobacco tissue cultures. Physiol Plant 15:473-497

Ouzounis T, Frette X, Rosenqvist E, Ottosen CO (2014) Spectral effects of supplementary lighting on the secondary metabolites in roses, chrysanthemums, and campanulas. J Plant Physiol 171(16):1491-1499

Ouzounis T, Razi PB, Frette X, Rosenqvist E, Ottosen CO (2015a) Predawn and high intensity application of supplemental blue light decreases the quantum yield of PSII and enhances the amount of phenolic acids, flavonoids, and pigments in Lactuca sativa. Front Plant Sci 6:19

Ouzounis T, Rosenqvist E, Ottosen C (2015b) Spectral effects of artificial light on plant physiology and secondary metabolism: a review. HortScience 52:12

Pavlovic A, Saganova M (2015) A novel insight into the cost-benefit model for the evolution of botanical carnivory. Ann Bot 115:1075-1092

Saito K, Mizukami H (2002) Plant cell cultures as producers of secondary compounds. Production of plant pigments. In: OksmanCaldentey K-M, Barz W (eds) Plant bio-technology and transgenic plants. CRC Press, Boca Raton, pp 84-94

Samuoliene G, Brazaityte A, Sirtautas R et al (2013) LED illumination affects bioactive compounds in romaine baby leaf lettuce. J Sci Food Agric 93:3286-3291

Shin KS, Murthy HN, Heo JW, Hahn EJ, Paek KY (2008) The effect of light quality on the growth and development of in vitro cultured Doritaenopsis plants. Acta Physiol Plant 30:339-343

Shohael AM, Ali MB, Yu KW, Hahn EJ, Islam R, Paek KY (2006) Effect of light on oxidative stress, secondary metabolites and induction of antioxidant enzymes in Eleutherococcus senticosus somatic embryos in bioreactor. Process Biochem 41:1179-1185

Shumbe L, Chevalier A, Legeret B, Taconnat L, Monnet F, Havaux M (2016) Singlet oxygen-induced cell death in Arabidopsis under high-light stress is controlled by OXI1 kinase. Plant Physiol 170(3):1757-1771

Silja PK, Gisha GP, Satheeshkumar K (2014) Enhanced plumbagin accumulation in embryogenic cell suspension cultures of Plumbago rosea $\mathrm{L}$. following elicitation. Plant Cell Tiss Organ Cult 119:469-477

Song Y, Li L (2018) Methods to study darkness-induced leaf senescence: plant senescence. Humana Press, New York

Swain T, Hillis WE (1959) Phenolic constituents of Prunus domestica. I: quantitative analysis of phenolic constituents. J Sci Food Agric 10:63-68

Szopa A, Ekiert H (2016) The importance of applied light quality on the production of lignans and phenolic acids in Schisandra chinensis (Turcz.) Baill. cultures in vitro. Plant Cell Tiss Organ Cult 127:115-121 
Szymanska R, Slesak I, Orzechowska A, Kruk J (2017) Physiological and biochemical responses to high light and temperature stress in plants. Environ Exp Bot 139:165-177

Taiz L, Zeiger E, Moller IM, Murphy A (2015) Plant physiology and development. Sinauer Associates, Inc., Cary

Takahashi S, Badger MR (2010) Photoprotection in plants: a new light on photosystem II damage. Trends Plant Sci 16:53-59

Tattini M, Guidi L, Morassi-Bonzi L et al (2005) On the role of flavonoids in the integrated mechanisms of response of Ligustrum vulgare and Phillyrea latifolia to high solar radiation. New Phytol 167:457-470

Thoren LM, Tuomi J, Kamarainen T, Laine K (2003) Resource availability affects investment in carnivory in Drosera rotundifolia. New Phytol 159:507-511

Tkalec M, Dobos M, Babic M, Jurak E (2015) The acclimation of carnivorous round-leaved sundew (Drosera rotundifolia L.) to solar radiation. Acta Physiol Plant 37:78

Tokunaga T, Takada N, Ueda M (2004) Mechanism of antifeedant activity of plumbagin, a compound concerning the chemical defense in carnivorous plant. Tetrahedron Lett 45:7115-7119

Torres-Franklin ML, Contour-Ansel D, Zuily-Fodil Y, Pham-Thi AT (2008) Molecular cloning of glutathione reductase cDNAs and analysis of GR gene expression in cowpea and common bean leaves during recovery from moderate drought stress. J Plant Physiol 165:514-521

Tsikas D (2017) Assessment of lipid peroxidation by measuring malondialdehyde (MDA) and relatives in biological samples: analytical and biological challenges. Anal Biochem 524:13-30
Walters RG (2005) Towards an understanding of photosynthetic acclimation. J Exp Bot 56:435-447

Wang CL, Guo QS, Zhu ZB, Cheng BX (2017) Physiological characteristics, dry matter, and active component accumulation patterns of Changium smyrnioides in response to a light intensity gradient. Pharm Biol 55(1):581-589

Wellburn AR (1994) The spectral determination of chlorophylls a and $\mathrm{b}$, as well as total carotenoids, using various solvents with spectrophotometers of different resolution. J Plant Physiol 144:307-313

Widhalm JR, Rhodes D (2016) Biosynthesis and molecular actions of specialized 1,4-naphthoquinone natural products produced by horticultural plants. Hort Res 3:1-17

Yang YL, Wang LT, Ma JH, Pham-Thi AT (2017) Effects of light quality on growth and development, photosynthetic characteristics and content of carbohydrates in tobacco (Nicotiana tabacum L.) plants. Photosynthetica 55:467

Yu W, Liu Y, Song L et al (2017) Effect of differential light quality on morphology, photosynthesis, and antioxidant enzyme activity in Camptotheca acuminata seedlings. J Plant Growth Reg 36(1):148-160

Zavafer A, Chow WS, Cheah MH (2015) The action spectrum of Photosystem II photoinactivation in visible light. J Photochem Photobiol B 152:247-260 